\title{
HISTOGENESIS OF THE MUSCULARIS MUCOSA IN THE HUMAN SMALL INTESTINE
}

\author{
Kaini Pfoze1, Kalpana Thounaojam²
}

${ }^{1}$ Associate Professor, Department of Anatomy, Jawaharlal Nehru Institute of Medical Sciences, Porompat, Imphal. ${ }^{2}$ Associate Professor, Department of Anatomy, Jawaharlal Nehru Institute of Medical Sciences, Porompat, Imphal.

ABSTRACT

\section{BACKGROUND}

The muscularis mucosa of the small intestine is absent in the early weeks of intrauterine life. It is reported to develop at about 16 weeks of gestational age.

The present study is an attempt to find out the exact time of appearance of the muscularis mucosa in the human small intestine.

\section{MATERIALS AND METHODS}

After obtaining clearance from the Ethics Committee, specimen of small intestine were procured from aborted foetuses and processed for histological observations. Haematoxylin and Eosin stain and Masson's Trichrome were used for staining the prepared slides.

\section{RESULTS}

The present study found out that the muscularis mucosa started appearing only at 18 weeks. The histological appearance at 24 weeks was similar to that of adult muscularis mucosa.

\section{CONCLUSION}

In the present study, the muscularis mucosa was not observed in the early weeks of gestation. Therefore, the mucosa and submucosa could not be demarcated from each other with clarity. But at 18 weeks of development, the muscularis mucosa could be demonstrated with the conventional H \& E stain. It was better stained and demonstrated clearly with Masson's Trichrome for connective tissue. With further staining and observation, the muscularis mucosa was found to be histologically comparable to that of an adult at 24 weeks of gestation.

\section{KEYWORDS}

Small Intestine, Histological Layers, Muscularis Mucosa, Time of Appearance.

HOW TO CITE THIS ARTICLE: Pfoze K, Thounaojam K. Histogenesis of the muscularis mucosa in the human small intestine. J. Evolution Med. Dent. Sci. 2016;5(84):6230-6233, DOI: 10.14260/Jemds/2016/1408

\section{BACKGROUND}

The small intestine consists of four histological layers. They are the mucosa, submucosa, muscularis externa and serosa or adventitia. The mucosa comprises an epithelial lining; an underlying connective tissue and a thin layer of smooth muscle called the muscularis mucosa. The muscularis mucosa demarcates the mucosa from the submucosa. The muscularis mucosa is a derivative of the splanchnopleuric mesoderm. ${ }^{1}$ It appeared relatively late and was seen in foetuses $80-240 \mathrm{~mm}$ CRL, corresponding to $15-26$ weeks gestation. ${ }^{2}$ Intestinal glands, the longitudinal musculature, the myentric plexus and the circular folds can be detected during the first trimester and they become well developed in the second trimester. ${ }^{3}$ The lamina propria became a separate layer with the appearance of muscularis mucosa at about 16 weeks. ${ }^{4}$ According to some authors, the muscularis mucosa could be observed only at 18 weeks. ${ }^{5}$

Financial or Other, Competing Interest: None.

Submission 17-06-2016, Peer Review 09-10-2016,

Acceptance 14-10-2016, Published 18-10-2016.

Corresponding Author:

Dr. Kaini Pfoze,

Department of Anatomy,

Jawaharlal Nehru Institute of Medical Sciences,

Porompat, Imphal East-795005,

Manipur.

E-mail: kainipfoze@yahoo.com

DOI: $10.14260 /$ jemds/2016/1408
Under the light microscope, the muscularis mucosa is represented by a thin layer of smooth muscle cells lining the lower limits of the intestinal glands. A few of its fibres penetrate the core of the intestinal villi. Embryologically, the muscularis mucosa is a derivative of the splanchnopleuric mesenchyme. Absent in the early weeks of development, the muscularis mucosa starts to appear at about 16 weeks of gestational age.

The present study is an attempt to find out the time of appearance of the muscularis mucosa and to observe its further development towards maturity.

\section{MATERIALS AND METHODS}

The present study was carried out in the Department of Anatomy, Regional Institute of Medical Sciences, Imphal. With due permission from the Ethical Society and proper consent of the concerned individuals 64 normal human foetuses, 36 males and 28 females representing different gestational ages ranging from 9 weeks to term were collected from the Department of Obstetrics and Gynaecology including PPP Centre, RIMS, Imphal. The foetuses were mostly stillbirths and a few were the products of induced abortions (under the provisions of the MTP Act of India, 1971).

Age of the foetuses was calculated from obstetrical history and by measuring the Crown-Rump Length (CRL). The foetuses were then divided into smaller groups according to their gestational age. The relationship among the group, gestational age in weeks and CRL is shown below. 


\begin{tabular}{|c|c|c|}
\hline Group & Gestational Age (Weeks) & CRL (mm) \\
\hline I & $9-12$ & $31-60$ \\
\hline II & $13-16$ & $61-100$ \\
\hline III & $17-20$ & $101-150$ \\
\hline IV & $21-24$ & $51-200$ \\
\hline V & $25-50$ & $201-450$ \\
\hline
\end{tabular}

\section{Procedure of Tissue Preparation}

Foetuses collected were dissected in the following manner. Subcostal incisions were given on either side to open up the anterior abdominal wall. The incisions were extended downward and medially to meet each other at the pubic symphysis. After removing the anterior abdominal wall, the small intestine was identified and gently taken out. The upper end was detached at the pyloric end of the stomach and the lower end was cut at the ileocaecal junction.

Short segments of the small intestine were cut and mesentery gently removed. The tissues were then subjected to tissue processing. Primary fixation was done in $10 \%$ Formalin for a period of 7-10 days followed by secondary fixation in Neutral Buffered Formalin. After satisfactory fixation, the tissues were trimmed and washed in 50\% Alcohol. This was followed by the normal procedure of Dehydration, Clearing, Paraffin embedding, Paraffin block making, Sectioning, Mounting, Rehydration and Staining.

The Rotary Microtome was used for making serial sections of the specimen.

\section{The Various Stains used were}

a. Haematoxylin and Eosin.

b. Masson's Trichrome.

The stained slides were examined under the Light Microscope and those slides showing specific findings were photographed and stored for record and presentation. The histological findings were then compiled and the results compared with the findings of previous researchers.

\section{RESULTS}

\section{Group A (9-12) Weeks}

The muscularis mucosa was not developed in the 9-12 weeks group (Fig. 1). No demarcation was observed between lamina propria and submucosa.

\section{Group B (13-16) Weeks}

In this group the other layers appeared well developed, but the muscularis mucosa was still not seen. Therefore, the mucosa did not appear separate from the submucosa (Fig. 2).

\section{Group C (17-20) Weeks}

In the 17-20 weeks group, the muscularis mucosa was observed as a thin layer of smooth muscle fibres. Some muscle fibres could be seen invading the core of the villi. Now a clear demarcation could be seen between the mucosa and the submucosa (Fig. 3).

\section{Group D (21-24) Weeks}

The muscularis mucosa appeared as a distinct layer in this group of 21-24 weeks (Fig. 4). The muscle layer appeared thicker and better developed than the previous group. At 24 weeks, the appearance of the muscularis mucosa was similar to that of an adult (Fig. 5).

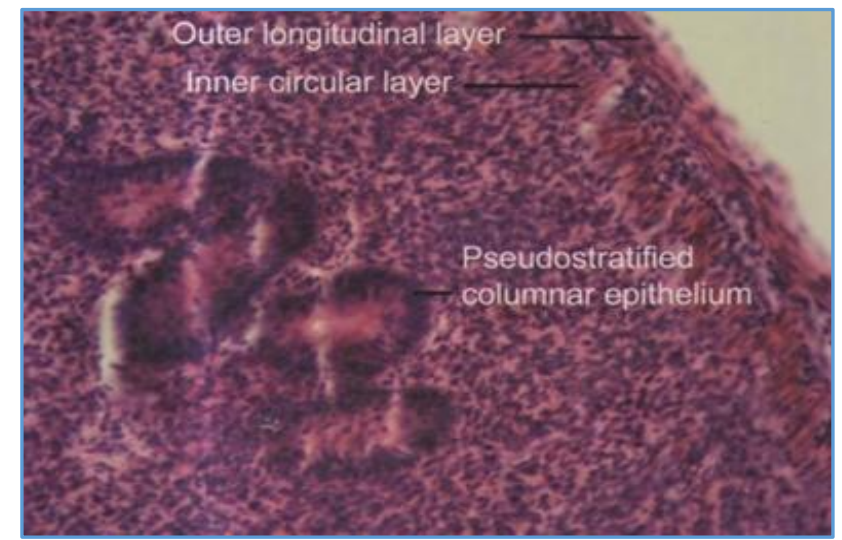

Figure 1. Longitudinal Section of Small Intestine at 12 Weeks (H\&E Stain)

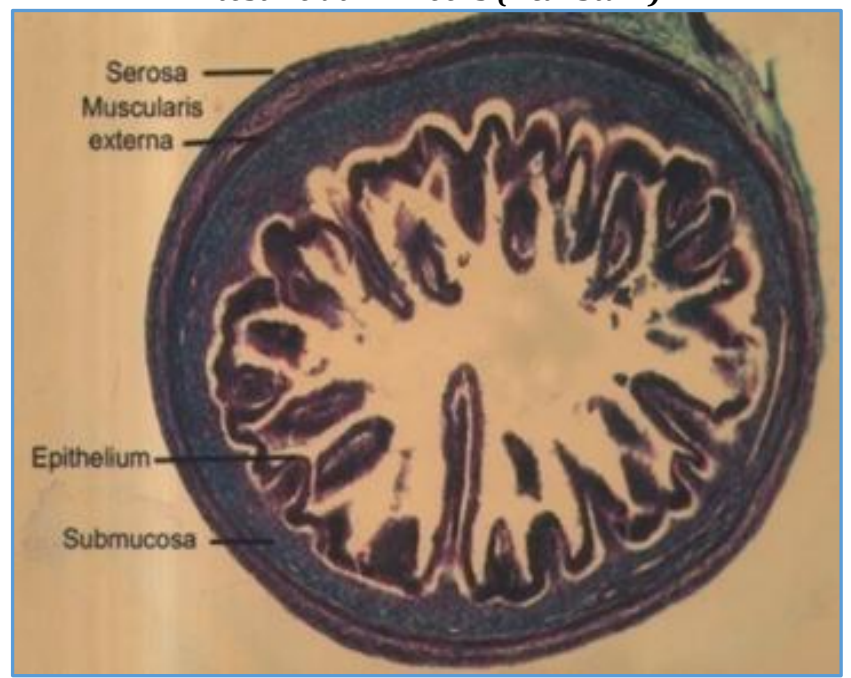

Figure 2. Cross Section of Small Intestine at 16 Weeks (Masson's Trichrome)

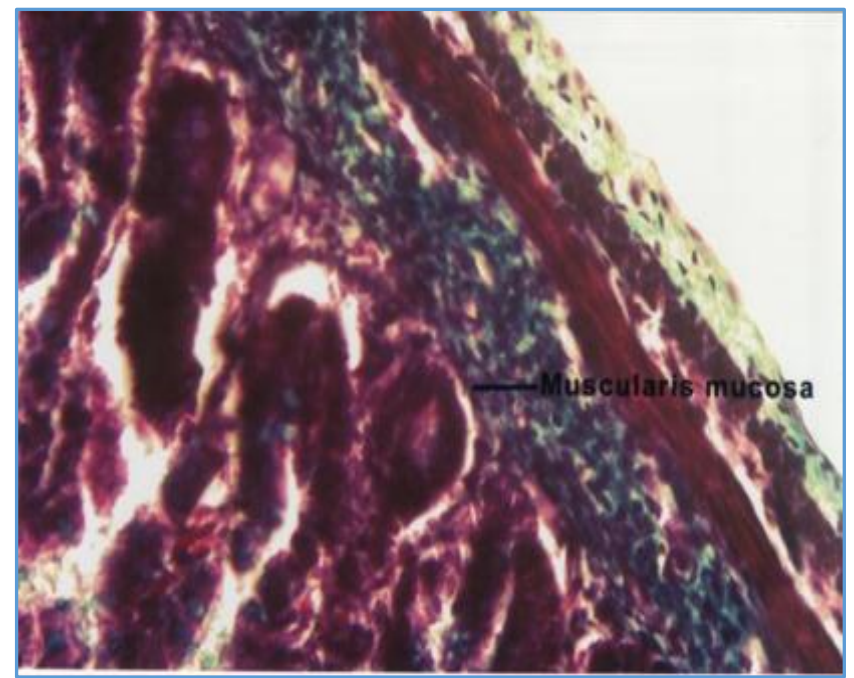

Figure 3. Transverse Section of Small Intestine at 18 Weeks (Masson's Trichrome) 


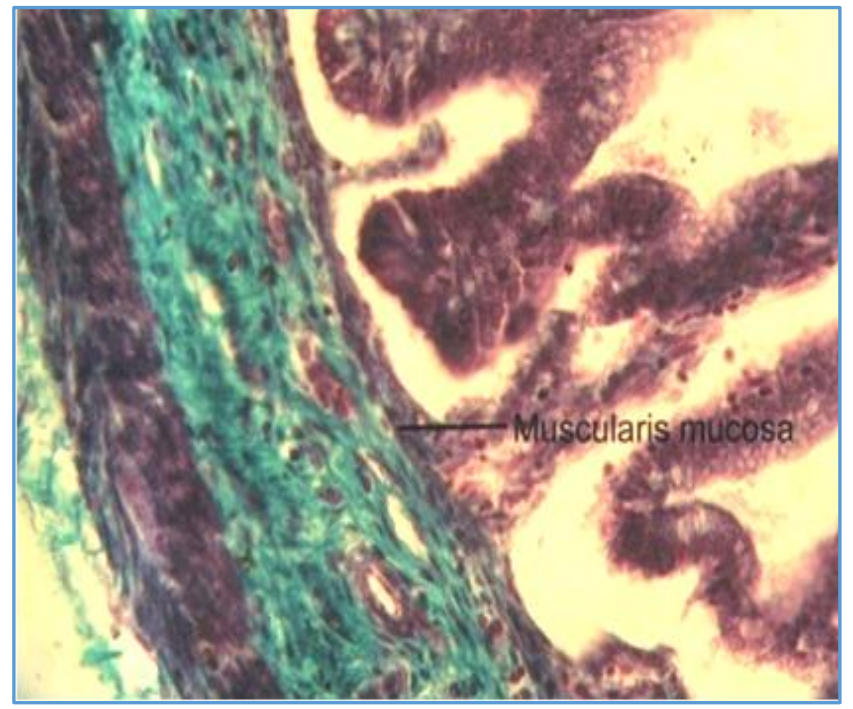

Figure 4. Oblique Section of Small Intestine at 24 Weeks (Masson's Trichrome)

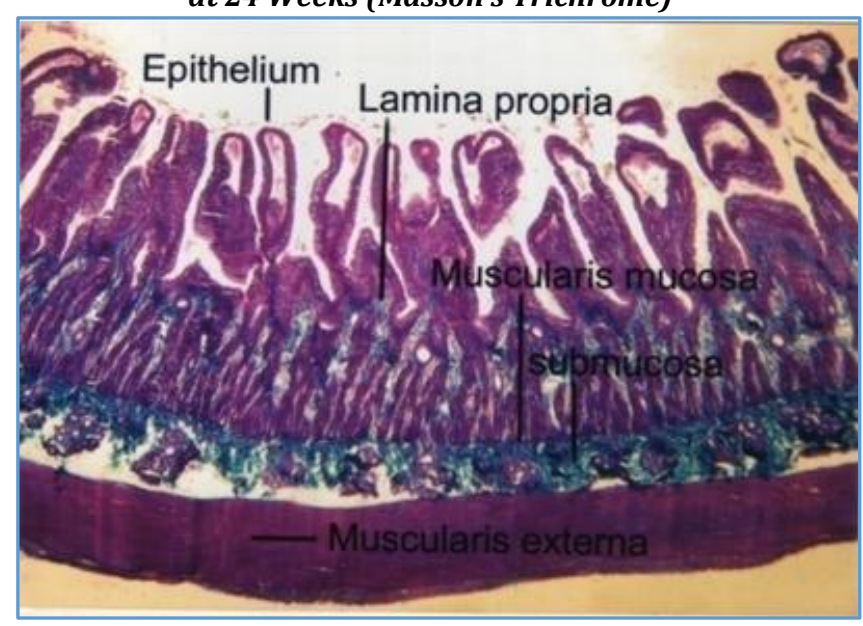

Figure 5. Transverse Section of Adult Small Intestine (Masson's Trichrome)

\section{DISCUSSION}

The intestinal wall consists of mucosa, submucosa, muscularis externa and serosa or adventitia. The mucosa is thick and very vascular in the proximal small intestine, but thinner and less vascular in the distal part. In part of its course, it is ridged by the underlying submucosa to form circular folds and the whole surface is covered by mucosal finger-like or leaf-like intestinal villi. Between the bases of the villi are numerous simple tubular intestinal glands, while in the duodenum there are also submucosal glands.

According to Cormack DH, the mucosa has three layers: epithelium, lamina propria and muscularis mucosa. Epithelium covers the intestinal villi and also the intestinal glands, which discharge the contents between the bases of the villi. Covering the surfaces of the villi are enterocytes, goblet cells and a few enteroendocrine cells. In localised areas covering the lymphoid tissues, another type, the microfold cell (M Cell) is also present in small numbers. The crypt epithelium consists Paneth cells, crypt base columnar cells, oligomucous cells and a few granulated enteroendocrine cells. ${ }^{6}$

The lamina propria is composed of connective tissue providing mechanical support for the epithelium. It has a rich vascular plexus. It also contains lymphoid tissue, fibroblast and connective tissue fibres, smooth muscle cells, eosinophilic leucocytes, macrophages, mast cells, capillaries, lymphatic vessels and non-myelinated nerve fibres.

The muscularis mucosa forms the base of the mucosa and demarcates the mucosa from the submucosa. It has an external longitudinal and inner circular layer of smooth muscle cells. It follows the surface profiles of the circular folds and sends fine fascicles of smooth muscle cells into the core of the villi. ${ }^{7}$ These muscle fibres can induce movements in the villi. This action increases the contacts of the villi with the digested food particles in the intestinal lumen. ${ }^{8}$ The muscularis mucosa lies immediately beneath the mucosal crypts and separates the mucosa from the submucosa. ${ }^{9}$

The muscularis mucosae allow local movements of the mucosa independent of other movement of the digestive tract, increasing contact of the lining epithelium with food. The contractions of the muscularis mucosa generated and coordinated by autonomic nervous plexuses, propel and mix the food in the digestive tract. The muscularis mucosa clearly demarcates the delicate lamina propria from the more robust underlying submucosa: this arrangement is typical of the whole gastrointestinal tract.

The muscularis mucosa is a thin layer of circumferentially oriented smooth muscle that corrects any displacement of the more superficial layers of the mucosa by contact with the intestinal contents. Its contraction also contributes to the movement of the villi.10 The muscularis mucosa is an area where gastrointestinal stromal tumours occur. Gastrointestinal stromal tumours are commonest in the stomach followed by the small intestine. ${ }^{11}$

\section{CONCLUSION}

In the present study, the muscularis mucosa was not observed in the early weeks of gestation. Therefore, the mucosa and submucosa could not be demarcated from each other with clarity. But at 18 weeks of development, the muscularis mucosa could be demonstrated with the conventional $\mathrm{H}$ \& $\mathrm{E}$ stain. It was better stained and demonstrated clearly with Masson's Trichrome for connective tissue. With further staining and observation, the muscularis mucosa was found to be histologically comparable to that of an adult at 24 weeks of gestation.

\section{REFERENCES}

1. Arey LB. The digestive tube and associated glands. $7^{\text {th }}$ edn. Developmental anatomy. WB Saunders Company, Philadelphia 1966:245-55.

2. Hamilton WJ, Mossman HW. Midgut and hindgut, hamilton, boyd and mossman's human embryology. $4^{\text {th }}$ edn. The macmillan press Ltd, London 1976:351-63.

3. O'Rahilly R, Muller F. The digestive system, human embryology and teratology. 2nd edn. Wiley-Liss Inc, New York 1996:207-33.

4. England MA. Midgut rotation, life before birth. $2^{\text {nd }}$ edn. Times mirror international publishers Ltd, London 1996:135-7.

5. Collins P. Development of midgut, Gray's anatomy. 39th edn. In: Standring S, Ellis H, Healy JC, et al. Churchill Livingstone, London 2005:1256-9.

6. Cormack DH. Small intestine, ham's histology. 9th edn. JB Lippincott company, Philadelphia 1987:501-13. 
7. Wigley C. Microstructure of the small intestine, Gray's anatomy. $3^{\text {th }}$ edn. In: Standring S, Ellis H, Healy JC, et al. Churchill Livingstone, London 2005:1157-69.

8. Eroschenko VP, di Fiore's. Atlas of histology with functional correlations. $11^{\text {th }}$ edn. Lippincott williams and wilkins 2005:341-2.

9. Fawcett DW. Intestines, a textbook of histology. $12^{\text {th }}$ edn. Chapmen and Hall, New York 1996:617-35.
10. Young B, Heath JW. Gastrointestinal tract, wheater's functional histology, a text and colour atlas. $4^{\text {th }}$ edn. Churchill Livingstone, London 2007:276-9.

11. Appleman HD. Smooth muscle tumours of the gastrointestinal tract. What we know now that stout didnt know. Am J Surg Pathol 1986;10(Suppl 1):83-99. 